\title{
AVALIAÇÃO DA QUALIDADE DO LEITE ATRAVÉS DE ANÁLISES FÍSICAS, QUÍMICAS, MICROBIOLÓGICAS E PESQUISA DE FRAUDES FRENTE AS NORMATIVAS 51/2002 E 62/2011
}

\author{
Keyla Cristiane Pereira Esper ${ }^{1}$ \\ Brenda Coimbra Silva ${ }^{2}$ \\ Odila Rigolin de Sá ${ }^{3}$
}

\begin{abstract}
RESUMO
Objetivou-se neste estudo oferecer aos produtores de leite, instrumentos de avaliação e gerenciamento de suas propriedades para que esses possam melhorar a qualidade do leite produzido e, atender Normativa 51/2002 e 62/2011; avaliar a contaminação do leite causada por mastite através da quantificação das células somáticas, avaliação microbiológica com a contagem de bactérias totais; avaliação física e química visando detectar as condições do produto e detectar fraudes por adição do soro e água. As coletas foram realizadas em duas propriedades leiteiras, quinzenalmente, com duplicata, no município e região de Passos/MG e levadas para análises no Laboratório de Análises Ambientais e Produtos Alimentícios da FESP/UEMG. As amostragens de leite foram realizadas nos tanques de resfriamento onde as amostras foram coletadas em frascos esterilizados com conservante bronopol para analise de contagem de células somáticas e composição e com conservante azidiol para análises microbiológicas. As análises microbiológicas foram executadas de acordo com a Instrução Normativa 62/2003 e as análises físicas e químicas de acordo com a Instrução Normativa 68/2006. As análises de contagem de células somáticas e composição foi por citometria de fluxo, a detecção de fraudes pelo método ninidrina acidificada, a adição de água pelo índice de crioscopia e pelo índice de refração. Algumas amostras demonstraram suas características físicas, químicas e microbiológicas fora dos padrões estabelecidos pela IN 51/2002 e 62/2011. Concluiu-se que de acordo com os resultados encontrados que os produtores precisam utilizar mais higienização no procedimento de ordenha, de equipamento e no manejo na obtenção de leite.
\end{abstract}

PALAVRAS-CHAVE: leite in natura, mastite, qualidade higiênico sanitário.

\section{EVALUATION OF MILK QUALITY THROUGH, CHEMICAL, MICROBIOLOGICAL AND PHYSICAL ANALYSIS OF RESEARCH FRAUD FRONT 51/2002 AND 62/2011 NORMATIVE}

\footnotetext{
${ }^{1}$ Bióloga graduada, FESP/UEMG. E-mail.keyla.pereira@gmail.com

${ }^{2}$ Graduanda, FESP/UEMG. E-mail.coimbras.brenda@gmail.com

3 Doutora, Dra em Ecologia e Recursos Naturais, coordenadora e professora do curso de Ciências Biológicas, FESP/UEMG. E-mail: odilarigolin@yahoo.com.br
} 


\begin{abstract}
The aim of this study provide milk producers, assessment tools and management of their properties so that these can improve the quality of milk produced and 51/2002 and 62/2011 Normative meet; evaluate the contamination of milk caused by mastitis through the quantification of somatic cells, microbiological evaluation with counting total bacteria; chemical and physical assessment to detect product conditions and detect fraud by the addition of serum and water. The collections were made in two dairy farms, fortnightly, with duplicate, in the county and region Steps / MG and taken for analysis at the Laboratory of Environmental Analysis and Food Products of HSPA / UEMG. Samples of milk were taken in cooling tanks where the samples were collected in sterilized jars with preservative bronopol for analysis of somatic cell count and composition and azidiol preservative for microbiological analyzes. Microbiological analyzes were performed according to Normative Instruction 62/2003 and the physical and chemical analysis according to Normative Instruction 68/2006. Analysis of somatic cell count and composition was by flow cytometry, detection of fraud by acidified ninhydrin method, the addition of water at freezing point index and the index of refraction. Some samples showed their physical, chemical and microbiological standards set out by the 51/2002 and 62/2011 IN features. It was concluded that according to the results found that producers need to use more cleaning the milking procedure, equipment and management in raising milk.
\end{abstract}

Keywords: fresh milk, mastitis, sanitary hygienic quality.

\title{
EVALUACIÓN DE LA CALIDAD DE LA LECHE A TRAVÉS, QUIIMICOS, MICROBIOLÓGICOS Y ANÁLISIS FÍSICO DE FRAUDE DE INVESTIGACIÓN 51/2002 Y 62/2011 FRENTE NORMATIVA
}

\begin{abstract}
RESUMEN
El objetivo de este estudio proporciono a los productores de leche, las herramientas necesarias para la evaluación y gestión de sus propriedades, así como la mejora de la calidad de la leche producida de acuerdo a la normativa 51/2002 y 62/2011; para evaluar la contaminación de la leche causada por la mastitis a través de la cuantificación de células somáticas; la evaluación microbiológica con recuento total de bacterias; una evaluación físico-química para detectar las condiciones del producto y com él, el fraude por adición de suero y/o agua. Se hicieron colectas quincenales por duplicado en dos granjas lecheras en los Passos y su región. Los análisis se llevaron a cabo en el Laboratório de Análises Ambientais e Produtos Alimentícios da FESP/UEMG. Las muestras de leche fueron tomadas en los tanques almacenamiento en frascos con bronopol como conservante para el recuento de células somáticas y su composición; y con azidiol como conservante para los análisis microbiológicos de enfriamiento. Los análisis microbiológicos se realizaron según la Instrucción Normativa 62/2003 y el análisis físico-químico de acuerdo con la Instrucción Normativa 68/2006. Los análisis de recuento de células somáticas y la composición se realizaron por citometría de flujo. Para la detección de fraude, se aplicó el método por acidificación de la ninhidrina. Mientras que para la detección de adición de agua se usó el índice del punto de congelación y el índice de refracción. Algunas muestras presentaron valores dentro de los índices de referencia estándar de la norma IN 51/2002 y 62/2011. De modo que se concluyó que, de acuerdo a los resultados, los productores precisan um mayor control en el procedimiento de la limpeza equipos de ordeño, y gestión de los produtos lácteos y el aumento de la producción de leche.
\end{abstract}

PALABRAS CLAVE: leche fresca, mastitis, higiénico sanitaria de calidad. 


\section{INTRODUÇÃO}

Pesquisas sobre as causas de alteração na produção e composição do leite no setor primário de produção, transporte e armazenamento são aspectos relevantes e servem como ferramenta para a melhoria da qualidade da matéria-prima e dos produtos lácteos, uma vez que o mercado consumidor está mais exigente e a demanda cada vez maior.

O setor leiteiro no Brasil vem passando por significativas mudanças nos últimos anos. Mas uma questão que vem preocupando autoridades, lideranças e pesquisadores é a qualidade do leite produzido no país. Leite de baixa qualidade causa grandes perdas econômicas ao setor, representa um risco à saúde pública, inviabiliza a conquista de mercados mais lucrativos e compromete a credibilidade da cadeia como um todo.

A qualidade do leite cru é influenciada por várias condições, destacando os fatores zootécnicos associados ao manejo, alimentação e potencial genético do rebanho, incluindo os fatores relacionados à obtenção e armazenamento do leite recém ordenhado. A qualidade do leite que chega à indústria de processamento é conseqüência da matéria-prima da propriedade de produção. Assim, os laticínios não podem melhorar a qualidade do leite cru que recebem.

O leite deve apresentar composição química (sólidos totais, gordura, proteína, lactose e minerais), microbiológica (contagem total de bactérias) que atenda aos parâmetros exigidos pela legislação brasileira de qualidade do leite, uma vez que, a composição físico-química está diretamente relacionada a fatores como raça, fisiologia, nutrição e estações do ano (ZANELA, 2006). Já a contagem de células somáticas (CCS) do leite coletado diretamente dos animais, quanto do leite granelizado é uma forma eficaz de monitoramento da prevalência de mastite subclínica no rebanho e é indicativa da qualidade do leite in natura destinado ao processamento de produtos lácteos em indústrias de laticínios, bem como das condições higiênicas sob as quais o leite foi produzido. Pode-se também, por meio da CCS estabelecer medidas de prevenção e de controle da mastite (GONZALES et al., 2004). 
As condições físico-químicas do leite envolvem diversos parâmetros que devem ser estudados em laboratório para a determinação de sua qualidade, valor nutricional, rendimento industrial e detecção de possíveis fraudes. As ocorrências mais generalizadas relacionam-se com a adição de água. Entretanto, as pesquisas de fraudes são realizadas visando detectar a presença de conservantes, neutralizantes e reconstituintes (PONSANO et al., 2001; OLIVEIRA, 2009). A legislação proíbe a adição de soro proveniente da fabricação de queijo ao leite de consumo. Entretanto, por estar quase sempre disponível, uma vez que é um coproduto de custo reduzido ou nulo, torna-se economicamente atrativa a adição deste ao leite (CARVALHO et al., 2007).

Objetivou-se neste estudo oferecer aos produtores de leite, instrumentos de avaliação e gerenciamento de suas propriedades para que esses possam melhorar a qualidade do leite produzido e, atender Normativa 51/2002 e 62/2011; avaliar a contaminação do leite causada por mastite através da quantificação das células somáticas, avaliação microbiológica com a contagem de bactérias totais; avaliação física e química visando detectar as condições do produto e detectar fraudes por adição do soro e água.

\section{MATERIAL E MÉTODO}

No município e região de Passos/MG, foram coletadas amostras de leite cru refrigerado em duas propriedades leiteiras. As propriedades foram: (A) circuito fechado com fosso, freestall e é produtora de 11.000 litros/dia de leite, localizada em São João Batista do Gloria/MG; (B) circuito fechado no mesmo nível e é produtora de 700 litros/dia de leite localizada em Passos/MG. As coletas foram realizadas, no mês de abril a agosto de 2014, duas vezes por mês, com duplicata, diretamente do tanque de resfriamento das propriedades leiteiras, onde as amostras foram coletadas em frascos estéreis com conservante bronopol para CCS e composição e com conservante azidiol para análise microbiológica. Posteriormente, as amostras foram conservadas em recipientes isotérmicos com gelo reciclável, com temperatura de refrigeração de aproximadamente $4^{\circ} \mathrm{C}$ e encaminhadas para análises laboratoriais no 
Laboratório de Análises Ambientais e Produtos Alimentícios - LAAPA, localizado na Fundação de Ensino Superior de Passos.

Para as análises de coliformes totais e termotolerantes foram utilizadas a técnica de tubos múltiplos, para coliformes totais foi utilizado o meio de cultura bacteriológica Caldo Lactosado Verde Brilhante e Bile $2 \%$ com incubação a $36^{\circ} \mathrm{C}$ durante 24 - 48 horas. Posteriormente as amostras positivas foram repicadas para tubos com caldo E.coli, utilizado para determinar a presença de coliformes termotolerantes em um período de 24 horas com incubação a $44,5^{\circ} \mathrm{C}$. Todas as amostras de coliformes foram determinadas utilizando o valor do Numero Mais Provavel - NMP/mL, como descrito no Compedium of Methods for the Microbiological Examination of Foods (VANDERZANT \& SPLITTSTOESSER, 1992).

A Contagem Bacteriana Total foi mensurada através da metodologia descrita no Compedium of Methods for the Microbiological Examination of Foods (Swanson et al. 2001) que constitui em quantificar um grupo de bactérias, presentes no leite por meio de inoculação da amostra em placas e, posteriormente, incubação à temperatura de $36^{\circ} \mathrm{C}$, por 48 horas. O meio de cultura utilizado nas placas foi o Plate Count Agar - PCA, que apresenta nutrientes que permitem a multiplicação bacteriana. O resultado foi obtido pela contagem das colônias e expresso em Unidade Formadora de Colônias - UFC.

Os parâmetros físicos e químicos realizados foram: $\mathrm{pH}$ realizada com o auxílio de um pHmêtro; Acidez Titulável utilizou o método Dornic ( $\left.{ }^{\circ} \mathrm{D}\right)$; Densidade utilizou o lactodensímetro; Teste do Alizarol utilizou o método acidímetro de Salut; Amido foi determinado com solução de Lugol; Redutase baseia-se na velocidade de redução da solução do azul de metileno, pela enzima redutase produzida por bactérias Barkworth (1959); o teste do álcool verificou a estabilidade do leite em presença de solução alcoólica, segundo Behmes (1999); a metodologia aplicada para a análise de identificação do soro seguiu os métodos de Prata et. al. (2004), o indice de refração foi determinado através do refratômetro acoplado a um ultra termostato a $20^{\circ} \mathrm{C} \mathrm{e} \mathrm{a}$ determinação de fraude por aguagem foi por crioscopia segundo International Dairy Federation, (1991). Para as análises de contagem de células somáticas, gordura, proteínas, lactose e sólidos totais foram realizados por citometria de fluxo, através do 
sistema combinado 2.300 da Bentley, extrato seco desengordurado foi estimado pela diferença entre extrato seco total e a porcentagem de gordura.

Os resultados das análises das amostras de leite foram comparados aos parâmetros da Normativa 51/2002 e 62/2011 para o leite cru refrigerado tipo B, devido aos produtores de leite possuir o sistema de ordenha mecânica, sendo seus objetivos produzirem o leite tipo $B$.

O conhecimento das características da ordenha e da produção de leite nas propriedades foi determinado através de um questionário pré-estabelecido.

\section{RESULTADOS E DISCUSSÃO}

A qualidade do leite está diretamente relacionada à saúde, alimentação e manejo dos animais, com a qualificação da mão-de-obra, higiene dos equipamentos e utensílios utilizados durante a ordenha, bem como o transporte adequado até a indústria (PINNA e LIZIEIRE, 2000).

Os resultados demonstrados a seguir são as médias das análises físicas, químicas e microbiológicas do leite realizada em duas propriedades leiteira no período de abril a agosto de 2014. Os resultados foram comparados com os parâmetros estabelecidos na Normativa 51/2002 e 62/2011, sendo nas tabelas destacados os valores que deram fora dos padrões com asterisco $\left({ }^{*}\right)$.

Tabela 01: Resultados das médias das análises físicas, químicas e microbiológicas das propriedades leiteiras A e B na primeira e segunda quinzena de abril 2012.

\begin{tabular}{c|c|c|c|c}
\hline PARÂMETROS & $\begin{array}{c}\text { PROPRIEDADE } \\
\text { LEITEIRA A } \\
1^{\circ} \text { Quinzena }\end{array}$ & $\begin{array}{c}\text { PROPRIEDADE } \\
\text { LEITEIRA B } \\
1^{\circ} \text { Quinzena }\end{array}$ & $\begin{array}{c}\text { PROPRIEDADE } \\
\text { LEITEIRA A } \\
2^{\circ} \text { Quinzena }\end{array}$ & $\begin{array}{c}\text { PROPRIEDADE } \\
\text { LEITEIRA B } \\
2^{\circ} \text { Quinzena }\end{array}$ \\
\hline Teste do Alizarol & Normal Estável & Normal Estável & Normal estável & Normal estável \\
\hline $\mathrm{pH}$ & 6,70 & 6,61 & 6,6 & 6,6 \\
\hline Teste do Álcool & Leite Normal & Leite Normal & Leite Normal & Leite Normal \\
\hline Densidade $(\mathrm{g} / \mathrm{mL})$ & 1,029 & 1,029 & 1,031 & 1,030 \\
\hline Amido & Ausência & Ausência & Ausência & Ausência \\
\hline Redutase & $\begin{array}{c}1^{\circ} \text { Classe: } \\
\text { Leite Bom }\end{array}$ & $\begin{array}{c}1^{\circ} \text { Classe: } \\
\text { Leite Bom }\end{array}$ & $\begin{array}{c}1^{\circ} \text { Classe: } \\
\text { Leite Bom }\end{array}$ & $\begin{array}{c}1^{\circ} \text { Classe: } \\
\text { Leite Bom }\end{array}$ \\
\hline Teor de gordura $(\mathrm{g} / 100 \mathrm{~g})$ & 3,8 & 4,05 & 3,9 & 4,0 \\
\hline Proteína $(\mathrm{g} / 100 \mathrm{~g})$ & 3,18 & 3,34 & 3,09 & 3,29 \\
\hline Lactose $(\%)$ & 4,84 & 4,74 & 4,80 & 4,70 \\
\hline Extrato seco total $(\%)$ & 12,31 & 12,77 & 12,76 & 12,68 \\
\hline
\end{tabular}




\begin{tabular}{c|c|c|c|c}
\hline $\begin{array}{c}\text { Extrato seco } \\
\text { desengordurado (\%) }\end{array}$ & 8,51 & 8,72 & 8,86 & 8,68 \\
\hline $\begin{array}{c}\text { Contagem de Células } \\
\text { Somáticas (ccs/mL) }\end{array}$ & 200.500 & 400.000 & 140.000 & 279.000 \\
\hline $\begin{array}{c}\text { Contagem Bacteriana } \\
\text { Total (UFC/mL) }\end{array}$ & $182.000^{*}$ & 650 & $180.000^{*}$ & 800 \\
\hline $\begin{array}{c}\text { Coliformes totais } \\
(\mathrm{NMP} / \mathrm{mL})\end{array}$ & $210^{*}$ & $6,1^{*}$ & $240^{*}$ & $11^{*}$ \\
\hline $\begin{array}{c}\text { Coliformes } \\
\text { termotolerantes (NMP/mL) }\end{array}$ & $150^{*}$ & $3,0^{*}$ & $240^{*}$ & $7,4^{*}$ \\
\hline Acidez titulável (Dornic) & 18,0 & 17,0 & 17,5 & 15 \\
\hline $\begin{array}{c}\text { Glicomacropeptídeo } \\
(\mu \mathrm{m} / \mathrm{mL})\end{array}$ & 2,35 & $4,00^{*}$ & 3,54 & $12,87^{*}$ \\
\hline Índice de refração & 1,3420 & $1,3422^{*}$ & 1,3420 & $1,3425^{*}$ \\
\hline Crioscopia ( $\left.{ }^{\circ} \mathrm{H}\right)$ & $-0,546$ & $-0,577^{*}$ & $-0,544$ & $-0,537$ \\
\hline
\end{tabular}

$\left(^{*}\right)$ Valores fora do padrão exigido pelas Normativas 51/2002 e 62/2011

Tabela 02: Resultados das médias das análises físicas, químicas e microbiológicas das propriedades leiteiras A e B na primeira e segunda quinzena de maio 2012.

\begin{tabular}{|c|c|c|c|c|}
\hline PARÂMETROS & $\begin{array}{c}\text { PROPRIEDADE } \\
\text { LEITEIRA A } \\
1^{\circ} \text { Quinzena }\end{array}$ & $\begin{array}{c}\text { PROPRIEDADE } \\
\text { LEITEIRA B } \\
1^{\circ} \text { Quinzena }\end{array}$ & $\begin{array}{c}\text { PROPRIEDADE } \\
\text { LEITEIRA A } \\
2^{\circ} \text { Quinzena } \\
\end{array}$ & $\begin{array}{c}\text { PROPRIEDADE } \\
\text { LEITEIRA B } \\
2^{\circ} \text { Quinzena }\end{array}$ \\
\hline Teste do Alizarol & Normal estável & Normal estável & Normal Estável & Normal estável \\
\hline $\mathrm{pH}$ & 6,6 & 6,62 & 6,65 & 6,60 \\
\hline Teste do Álcool & Leite Normal & Leite Normal & Leite Normal & Leite Normal \\
\hline Densidade $(\mathrm{g} / \mathrm{mL})$ & 1,028 & 1,031 & 1,028 & 1,030 \\
\hline Amido & Ausência & Ausência & Ausência & Ausência \\
\hline Redutase & $\begin{array}{l}1^{\circ} \text { Classe: } \\
\text { Leite Bom }\end{array}$ & $\begin{array}{l}1^{\circ} \text { Classe: } \\
\text { Leite Bom }\end{array}$ & $\begin{array}{l}1^{\circ} \text { Classe: } \\
\text { Leite Bom }\end{array}$ & $\begin{array}{l}1^{\circ} \text { Classe: } \\
\text { Leite Bom }\end{array}$ \\
\hline Teor de gordura $(\mathrm{g} / 100 \mathrm{~g})$ & 4,0 & 4,42 & 3,56 & 4,39 \\
\hline Proteína $(\mathrm{g} / 100 \mathrm{~g})$ & 2,95 & 3,40 & 3,0 & 3,30 \\
\hline Lactose (\%) & 4,79 & 4,72 & 4,58 & 4,62 \\
\hline Extrato seco total (\%) & 12,5 & 13,23 & 13,0 & 12,90 \\
\hline $\begin{array}{c}\text { Extrato seco } \\
\text { desengordurado (\%) }\end{array}$ & 8,5 & 8,81 & 9,44 & 8,51 \\
\hline $\begin{array}{l}\text { Contagem de Células } \\
\text { Somáticas (ccs/mL) }\end{array}$ & 217.000 & 385.000 & 152.000 & 348.000 \\
\hline $\begin{array}{c}\text { Contagem Bacteriana } \\
\text { Total (UFC/mL) }\end{array}$ & $620.000^{*}$ & $270.000^{*}$ & $300.000^{*}$ & $200.000^{*}$ \\
\hline $\begin{array}{c}\text { Coliformes totais } \\
(\mathrm{NMP} / \mathrm{mL})\end{array}$ & $>1100^{*}$ & $1100^{*}$ & $460^{*}$ & $210^{*}$ \\
\hline $\begin{array}{c}\text { Coliformes } \\
\text { termotolerantes }(\mathrm{NMP} / \mathrm{mL})\end{array}$ & $1100^{*}$ & $460^{*}$ & $240^{*}$ & $150^{*}$ \\
\hline Acidez titulável (Dornic) & 18,0 & 18 & 17 & 18 \\
\hline $\begin{array}{c}\text { Glicomacropeptídeo } \\
(\mu \mathrm{g} / \mathrm{mL})\end{array}$ & $0,89^{*}$ & 3,01 & $6,21^{*}$ & 2,47 \\
\hline Índice de refração & 1,3420 & 1,3415 & 1,342 & 1,342 \\
\hline Crioscopia $\left({ }^{\circ} \mathrm{H}\right)$ & $-0,538$ & $-0,542$ & $-0,515^{*}$ & $-0,535$ \\
\hline
\end{tabular}

$\left({ }^{*}\right)$ Valores fora do padrão exigido pelas Normativas 51/2002 e 62/2011 
Tabela 03: Resultados das médias das análises físicas, químicas e microbiológicas das propriedades leiteiras A e B na primeira e segunda quinzena de junho de 2012.

\begin{tabular}{|c|c|c|c|c|}
\hline PARÂMETROS & $\begin{array}{l}\text { PROPRIEDADE } \\
\text { LEITEIRA A } \\
1^{\circ} \text { Quinzena }\end{array}$ & $\begin{array}{l}\text { PROPRIEDADE } \\
\text { LEITEIRA B } \\
1^{\circ} \text { Quinzena }\end{array}$ & $\begin{array}{l}\text { PROPRIEDADE } \\
\text { LEITEIRA A } \\
2^{\circ} \text { Quinzena }\end{array}$ & $\begin{array}{c}\text { PROPRIEDADE } \\
\text { LEITEIRA B } \\
2^{\circ} \text { Quinzena }\end{array}$ \\
\hline Teste do Alizarol & Normal Estável & Normal Estável & Normal Estável & Normal Estável \\
\hline $\mathrm{pH}$ & 6,63 & 6,60 & 6,60 & 6,60 \\
\hline Teste do Álcool & Leite Normal & Leite Normal & Leite Normal & Leite Normal \\
\hline Densidade $(\mathrm{g} / \mathrm{mL})$ & 1,028 & 1,029 & 1,030 & 1,027 \\
\hline Amido & Ausência & Ausência & Ausência & Ausência \\
\hline Redutase & $\begin{array}{l}1^{\circ} \text { Classe: } \\
\text { Leite Bom }\end{array}$ & $\begin{array}{l}1^{\circ} \text { Classe: } \\
\text { Leite Bom }\end{array}$ & $\begin{array}{l}1^{\circ} \text { Classe: } \\
\text { Leite Bom }\end{array}$ & $\begin{array}{l}1^{\circ} \text { Classe: } \\
\text { Leite Bom }\end{array}$ \\
\hline Teor de gordura $(\mathrm{g} / 100 \mathrm{~g})$ & 3,5 & 3,89 & 4,26 & 3,0 \\
\hline Proteína $(\mathrm{g} / 100 \mathrm{~g})$ & 2,49 & 3,15 & 3,80 & 2,9 \\
\hline Lactose (\%) & 4,14 & 4,46 & 4,49 & 4,68 \\
\hline Extrato seco total (\%) & 12,6 & 12,60 & 13,13 & 12,0 \\
\hline $\begin{array}{c}\text { Extrato seco } \\
\text { desengordurado (\%) }\end{array}$ & 9,1 & 8,71 & 8,87 & 9,0 \\
\hline $\begin{array}{l}\text { Contagem de Células } \\
\text { Somáticas (ccs/mL) }\end{array}$ & 239.000 & 105.000 & 290.000 & 28.500 \\
\hline $\begin{array}{c}\text { Contagem Bacteriana } \\
\text { Total (UFC/mL) }\end{array}$ & $240.000^{*}$ & 97.000 & 148.000* & $200.000^{*}$ \\
\hline $\begin{array}{c}\text { Coliformes totais } \\
(\mathrm{NMP} / \mathrm{mL})\end{array}$ & $1100^{*}$ & 460 & $7,2^{*}$ & $210^{*}$ \\
\hline $\begin{array}{c}\text { Coliformes } \\
\text { termotolerantes (NMP/mL) }\end{array}$ & $460^{*}$ & $93^{*}$ & $3,6^{*}$ & $150^{*}$ \\
\hline Acidez titulável & 18 & 15 & 15 & 15 \\
\hline $\begin{array}{c}\text { Glicomacropeptídeo } \\
(\mu \mathrm{g} / \mathrm{mL})\end{array}$ & 2,16 & $1,52^{*}$ & $8,1^{*}$ & 1,92 \\
\hline Índice de refração & 1,3423 & 1,3425 & $1,3412^{*}$ & $1,3430^{*}$ \\
\hline Crioscopia $\left({ }^{\circ} \mathrm{H}\right)$ & $-0,558^{*}$ & $-0,557^{*}$ & $-0,717^{*}$ & $-0,535$ \\
\hline
\end{tabular}

${ }^{*}$ ) Valores fora do padrão exigido pelas Normativas 51/2002 e 62/2011

Tabela 04: Resultados das médias das análises físicas, químicas e microbiológicas das propriedades leiteiras na primeira e segunda quinzena de julho de 2012.

\begin{tabular}{c|c|c|c|c}
\hline PARÂMETROS & $\begin{array}{c}\text { PROPRIEDADE } \\
\text { LEITEIRA A } \\
1^{\circ} \text { Quinzena }\end{array}$ & $\begin{array}{c}\text { PROPRIEDADE } \\
\text { LEITEIRA B } \\
1^{\circ} \text { Quinzena }\end{array}$ & $\begin{array}{c}\text { PROPRIEDADE } \\
\text { LEITEIRA A } \\
2^{\circ} \text { Quinzena }\end{array}$ & $\begin{array}{c}\text { PROPRIEDADE } \\
\text { LEITEIRA B } \\
2^{\circ} \text { Quinzena }\end{array}$ \\
\hline Teste do Alizarol & Normal estável & Normal estável & Normal estável & Normal estável \\
\hline $\mathrm{pH}$ & 6,60 & 6,60 & 6,6 & 6,7 \\
\hline Teste do Álcool & Leite Normal & Leite Normal & Leite Normal & Leite Normal \\
\hline Densidade $(\mathrm{g} / \mathrm{mL})$ & 1,031 & 1,028 & 1,028 & 1,028 \\
\hline Amido & Ausência & Ausência & Ausência & Ausência \\
\hline Redutase & $\begin{array}{c}1^{\circ} \text { Classe: } \\
\text { Leite Bom }\end{array}$ & $\begin{array}{c}1^{\circ} \text { Classe: } \\
\text { Leite Bom }\end{array}$ & $\begin{array}{c}1^{\circ} \text { Classe: } \\
\text { Leite Bom }\end{array}$ & $1^{\circ}$ Classe: \\
Leite Bom
\end{tabular}




\begin{tabular}{c|c|c|c|c}
\hline $\begin{array}{c}\text { Extrato seco } \\
\text { desengordurado (\%) }\end{array}$ & 8,5 & 8,61 & 8,58 & 8,6 \\
\hline $\begin{array}{c}\text { Contagem de Células } \\
\text { Somáticas (ccs/mL) }\end{array}$ & 390.000 & 100.000 & 365.500 & 27.500 \\
\hline $\begin{array}{c}\text { Contagem Bacteriana } \\
\text { Total (UFC/mL) }\end{array}$ & $1.470 .000^{*}$ & $780.000^{*}$ & $290.000^{*}$ & $290.000^{*}$ \\
\hline $\begin{array}{c}\text { Coliformes totais } \\
\text { (NMP/mL) }\end{array}$ & $>1.100^{*}$ & $460^{*}$ & $160^{*}$ & $14^{*}$ \\
\hline $\begin{array}{c}\text { Coliformes } \\
\text { termotolerantes (NMP/mL) }\end{array}$ & $>1.100^{*}$ & $460^{*}$ & $120^{*}$ & $9,2^{*}$ \\
\hline Acidez titulável (Dornic) & 17 & 17 & 15 & $1,35^{*}$ \\
\hline $\begin{array}{c}\text { Glicomacropeptídeo } \\
(\mu g / m L)\end{array}$ & 2,52 & $1,37^{*}$ & $1,42^{*}$ & $1,3445^{*}$ \\
\hline Índice de refração & 1,3420 & $1,3425^{*}$ & $1,3425^{*}$ & $-0,575^{*}$ \\
\hline Crioscopia ('H) & $-0,549$ & $-0,556^{*}$ & $-0,512^{*}$ & 1, \\
\hline
\end{tabular}

$\left(^{*}\right)$ Valores fora do padrão exigido pelas Normativas 51/2002 e 62/2011

Tabela 05: Resultados das médias das análises físicas, químicas e microbiológicas das propriedades leiteiras na primeira e segunda quinzena de agosto de 2012.

\begin{tabular}{|c|c|c|c|c|}
\hline PARÂMETROS & $\begin{array}{l}\text { PROPRIEDADE } \\
\text { LEITEIRA A } \\
1^{\circ} \text { Quinzena }\end{array}$ & $\begin{array}{l}\text { PROPRIEDADE } \\
\text { LEITEIRA B } \\
1^{\circ} \text { Quinzena }\end{array}$ & $\begin{array}{l}\text { PROPRIEDADE } \\
\text { LEITEIRA A } \\
2^{\circ} \text { Quinzena }\end{array}$ & $\begin{array}{l}\text { PROPRIEDADE } \\
\text { LEITEIRA B } \\
2^{\circ} \text { Quinzena }\end{array}$ \\
\hline Teste do Alizarol & Normal estável & Normal estável & Normal estável & Normal estável \\
\hline $\mathrm{pH}$ & 6,69 & 6,58 & 6,61 & 6,7 \\
\hline Teste do Álcool & Leite Normal & Leite Normal & Leite Normal & Leite Normal \\
\hline Densidade $(\mathrm{g} / \mathrm{mL})$ & 1,030 & 1,030 & 1,030 & 1,028 \\
\hline Amido & Ausência & Ausência & Ausência & Ausência \\
\hline Redutase & $\begin{array}{l}1^{\circ} \text { Classe: } \\
\text { Leite Bom }\end{array}$ & $\begin{array}{l}1^{\circ} \text { Classe: } \\
\text { Leite Bom }\end{array}$ & $\begin{array}{l}1^{\circ} \text { Classe: } \\
\text { Leite Bom }\end{array}$ & $\begin{array}{l}1^{\circ} \text { Classe: } \\
\text { Leite Bom }\end{array}$ \\
\hline Teor de gordura $(\mathrm{g} / 100 \mathrm{~g})$ & 4,0 & 4,55 & 4,32 & 4,00 \\
\hline Proteína $(\mathrm{g} / 100 \mathrm{~g})$ & 3,53 & 3,09 & 3,20 & 2,9 \\
\hline Lactose (\%) & 4,37 & 4,79 & 4,31 & 4,70 \\
\hline Extrato seco total (\%) & 12,78 & 13,05 & 13,2 & 13,12 \\
\hline $\begin{array}{c}\text { Extrato seco } \\
\text { desengordurado (\%) }\end{array}$ & 8,78 & 8,5 & 8,88 & 9,12 \\
\hline $\begin{array}{l}\text { Contagem de Células } \\
\text { Somáticas (ccs/mL) }\end{array}$ & 400.000 & 221.000 & 210.000 & 28.000 \\
\hline $\begin{array}{l}\text { Contagem Bacteriana } \\
\text { Total (UFC/mL) }\end{array}$ & $410.000^{*}$ & $600.000^{*}$ & $120.000^{*}$ & 90.000 \\
\hline $\begin{array}{l}\text { Coliformes totais } \\
(\mathrm{NMP} / \mathrm{mL})\end{array}$ & $>1100 *$ & $>1100 *$ & 210 * & $6,1^{*}$ \\
\hline $\begin{array}{c}\text { Coliformes } \\
\text { termotolerantes } \\
(\mathrm{NMP} / \mathrm{mL})\end{array}$ & 89 * & 185 * & $160^{*}$ & $3,0^{*}$ \\
\hline Acidez titulável (Dornic) & 18 & 16 & 17 & 15 \\
\hline $\begin{array}{c}\text { Glicomacropeptídeo } \\
(\mu \mathrm{g} / \mathrm{mL})\end{array}$ & $9,51^{*}$ & $7,32^{*}$ & $0,35^{*}$ & 3,45 \\
\hline Índice de refração & $1,3430^{*}$ & $1,3428^{*}$ & 1,3420 & 1,3420 \\
\hline Crioscopia $\left({ }^{\circ} \mathrm{H}\right)$ & $-0,515^{*}$ & $-0,531$ & $-0,544$ & $-0,544$ \\
\hline
\end{tabular}

$\left(^{*}\right)$ Valores fora do padrão exigido pelas Normativas 51/2002 e 62/2011 
Observou-se que das 40 amostras de leite cru refrigerado coletadas, 32 (80\%) apresentaram contagem bacteriana total (CBT) superiores ao limite estabelecido pela Instrução Normativa 62/2011 que até 100.000 UFC/mL.

Foi observada a presença de coliformes, em 100\% das amostras de leite analisadas no período, apesar de não estarem presentes na normativa, as análises de coliformes foram realizadas para obter um controle da qualidade higiênico sanitária no manejo, nos equipamentos. A presença de coliformes segundo SILVA (1997) é considerada uma indicação útil de contaminação pós-sanitização ou pós-processo, evidentemente práticas de higiene e sanificação aquém dos padrões requeridos para o processo de alimentos.

A grande quantidade de amostras contaminadas por coliformes contribuiu para que os valores de CBT estivesse com mais amostras fora do padrão, indicando falta de prática de higiene. A Contagem Bacteriana Total (CBT) reflete a higiene do animal, do ambiente, dos equipamentos, dos procedimentos de ordenha e do resfriamento. É de extrema importância já que, considerando o potencial de se multiplicarem, as bactérias do leite podem causar alterações, tais como a degradação de gorduras, proteínas ou carboidratos, podendo tornar o produto impróprio para o consumo e processamento industrial (COUSIN, 1982).

A contaminação dos produtos lácteos por bactérias CBT pode originar-se do suprimento de água de qualidade inadequada, deficiências de procedimentos de higiene e mastite (ENEROTH, et al, 2000). Portanto, procedimentos de higienização empregados na cadeia produtiva do leite constituem pontos críticos para a obtenção de uma matéria-prima de alta qualidade.

A ocorrência de resultados elevados pode indicar existência de falhas generalizadas nos procedimentos de ordenha e refrigeração do leite na propriedade (BRAMLEY E MCKINNON, 1990; MARSHALL, 1991; MURPHY E BOOR, 1998; SORIANO et al 2001). A suposição de falhas na higiene de ordenha reforça-se pelos resultados obtidos no estado de Goiás por Andrade (1997) e Dias Filho (1997) que constataram procedimentos inadequados por parte dos ordenhadores e comprovaram sua relação com a qualidade do leite. A falta de realização adequada da limpeza e 
sanitização do tanque de refrigeração também contribuem para o comprometimento da qualidade microbiológica do leite (MENDONÇA et al., 2001a).

Picinim (2003), após determinar a Contagem Bacteriana Total (CBT) em amostras de leite cru refrigerado e estocado em tanques no Estado de Minas Gerais, verificou que $74,19 \%$ das amostras apresentavam CBT dentro do padrão preconizado pela IN 51 para 2005, que era de $1,00 \times 10^{6} \mathrm{UFC} / \mathrm{mL}$. Ainda com base no autor, os parâmetros estabelecidos para 2008, que era $7,5 \times 10^{5} \mathrm{UFC} / \mathrm{mL}, 67,74 \%$ das amostras analisadas, apresentaram resultados que atenderiam ao requisito proposto pela IN 51 e, apenas $25,81 \%$ dos resultados estariam de acordo com o padrão estabelecido pela IN 51 para o ano de 2011 que é $1,00 \times 10^{5} \mathrm{UFC} / \mathrm{mL}$.

Foi observado também alterações nos parâmetros para detectar fraudes e adulterações no leite. Das 40 amostras de leite cru coletadas para análise de glicomacropeptídio para verificação de adição de soro encontrou-se 12 (30\%) amostras de leite com valores acima de 3,54 $\mu \mathrm{g} / \mathrm{mL}$ e 12 (30\%) amostras de leite com valores abaixo de 1,88 $\mu \mathrm{g} / \mathrm{mL}$ segundo determinação de Prata 2001.

A fraude por adição de soro ao leite deixa uma "impressão digital", que é a presença de glicomacropeptídeo em níveis elevados que permanecem solúveis no soro (PRATA, 2001).

Constitui a base da maior parte dos métodos desenvolvidos para detectar e coibir esse tipo de fraude (PRATA, 2002). A Glicomacropeptídeo é uma proteína de presença natural existente no leite, sua quantificação em níveis elevados caracteriza a presença de soro no leite.

O índice crioscópico do leite é tido como uma propriedade física que apresenta uma variação muito pequena, mas é possível ocorrer mediante modificações na dieta alimentar do rebanho leiteiro, período de lactação, estação do ano entre outros fatores, bem como a fraude, ou seja, adição intencional de água ao mesmo. Em virtude disto este parâmetro é utilizado como um dos critérios de desclassificação de leite para o consumo humano (TRONCO, 1997).

Das 40 amostras de leite cru analisados para crioscopia 12 (30\%) apresentaram valores acima do permitido pela normativa $51 / 2002$ que é de $-0,550^{\circ} \mathrm{H}$ 
isto significa que ocorreu fraude por reconstituintes e 6 (15\%) estão abaixo de $0,530^{\circ} \mathrm{H}$, isto é, ocorreu fraude por aguagem no leite.

A água, além de diluir os componentes naturais do leite, pode representar um grande risco de contaminação do mesmo, segundo as condições que foram obtidas para adição. Microorganismos, uma vez introduzidos no leite, encontram um "habitat" ideal para o seu desenvolvimento. (COUTO, 2002).

FREIRE, 2006 analisou 48 amostras de leite cru refrigerado, onde apenas 2 tiveram seu índice crioscópico fora dos padrões de conformidade, o que sugere um indicativo de fraude, provavelmente por aguagem, já que os níveis encontrados estavam mais próximos ao ponto de congelamento da água. As demais amostras (41) apresentaram conforme o padrão definido de índice crioscópico estabelecido pela Instrução Normativa № 51 ,

Foram submetidas à análise de Índice de Refração 40 amostras de leite, das quais 9 (22,5\%) deram resultados fora do padrão exigido pela Normativa 51 (2002). 0 índice de refração do leite a $20^{\circ} \mathrm{C}$ se situa em torno de 1,3420 e aumenta com a concentração do mesmo.

\section{CONCLUSÃO}

A avaliação da qualidade do leite através de análises físicas, químicas e microbiológicas e pesquisa de fraudes permitiu constatar que todas as amostras apresentassem irregularidades em pelo menos um dos quesitos analisados e comparados frente às IN 51/2002 e 62/2011. As amostras com a alta porcentagem de CCS e CBT e a provável fraude por adição de água e reconstituintes foram os principais problemas observados. Os resultados encontrados indicam possível falta de higiene no processo de ordenha, saúde do úbere, do armazenamento e coleta do leite.

As boas práticas de produção de leite foram elaboradas com acompanhamentos e orientações aos produtores através da entrega de laudos mensais, com discussão dos resultados para determinar os pontos críticos de contaminação. 


\section{REFERÊNCIAS}

ANDRADE, M.A. Mastite Bovina Subclínica: prevalência, etiologia e freqüência de patógenos isolados das mãos de ordenhadores e teteiras, e testes de sensibilidade a drogas antimicrobianas. 1997. $113 \mathrm{f}$. Dissertação (Mestrado em Medicina Veterinária) - Escola de Veterinária - Universidade Federal de Goiás, 1997.

BARKWOORTH, H. 1959. Comparing two milk tests. Dairy Industries., May: 343-346.

BEHMES, M. L. Arruda. Tecnologia do Leite: Produção e Industrialização e análises. $13^{\circ}$ Ed. Ver, 1999.

BRAMLEY, A.J.; McKINNON, C.H. The microbiology of raw milk. In: ROBINSON, R.K. Dairy Microbiology: The microbiology of milk. 2. ed. Barking: Elsevier Science Publishers, p.163-208. 1990.

CARVALHO, B. M. A.de; CARVALHO, L. M.de; ALCÂNTRA, L. A. P.; BONOMO, R. C. F. Métodos de detecção de fraude em leite por adição de soro de queijo. Revista Electrónica de Veterinária, v. 8, n. 6, p. 1695-7504, 2007.

COUSIN, M. A. Presence and activity psychrotrophic microorganisms in milk and dairy products.Journal of Food Protection, v.45, p.172, 1982.

COUTO, Marco Antônio. Principais dúvidas sobre a produção de leite - 03/11/2002. Disponível em WWW.cienciadoleite.com.br, acessado em 13/12/2002.

DIAS FILHO, F.C. Perfil do produtor e características das propriedades rurais que utilizam ordenhadeira mecânica na bacia leiteira de Goiânia-GO. 1997. 63p. Dissertação (Mestrado em Medicina Veterinária) - Escola de Veterinária - Universidade Federal de Goiás, 1997.

ENEROTH, A. et al. Contamination of milk with Gram-negative spoilage bacteria during filling of retail containers. International Journal of Food Microbiology, v.57, p.99-106, 2000.

FREIRE, F. M. ANÁLISE DAS CARACTERÍSTICAS FÍSICO-QUÍMICAS DE LEITE CRU REFRIGERADO ENTREGUE EM UMA COOPERATIVA NO ESTADO DO RIO DE JANEIRO NO ANO DE 2002. Trabalho Monográfico de Pós Graduação. Rio de Janeiro, 2006.

GONZALEZ, H. L. et al. Avaliação da Qualidade do Leite na Bacia Leiteira de Pelotas, RS. Efeito dos Meses do Ano. Revista Brasileira de Zootecnia, Viçosa, v. 33, n. 6, p. 1531-1543, 2004.

INTERNATIONAL DAIRY FEDERATION.108 B:1991: milk: determination of freezing point (thermistor cryospe method). Brussels, 1991. $3 \mathrm{f}$. 
MENDONÇA, A.H.;CERQUEIRA, M.M.O.P.; CAMARGOS, C.R.M. et al. Qualidade físico-química de leite cru resfriado: comparação de diferentes procedimentos e locais de coleta. In: Congresso Nacional de Laticínios, 18., 2001, Juiz de Fora. Anais...Juiz de Fora: Templo. 2001.p.276-282.

MARSHALL, J. Differential diagnosis of high TBC. In Practice, v. 13, n. 5, p. 198-201, 1991.

MURPHY, S.C.; BOOR, K.J. Raw milk bacteria tests and elevated bactéria counts on the farm: a review. PANAMERICAN CONGRESS ON MASTITIS CONTROL AND MILK QUALITY, 1998, Merida. Proceedings..., ..p. 232-235. 1998.

PINNA, M.H.; LIZIEIRE, R.S. Leite de qualidade. Revista do Conselho Federal de Medicina Veterinária, Brasília, v. 21, p. 47-51, 2000.

PICININ, L. C. A.; CERQUEIRA, M. M. O. P.; SOUZA, M. R.; PENA, C. F. A. M. Diagnóstico de situação de contagem de células somáticas no leite cru refrigerado de algumas propriedades leiteiras de Minas Gerais. In: I CONGRESSO LATINO-AMERICANO DE HIGIENISTAS DE ALIMENTOS E VII CONGRESSO BRASILEIRO DE HIGIENISTAS DE ALIMENTOS, 2003, Belo Horizonte. Anais... Belo Horizonte, 2003.

PRATA, L.F. Fundamentos de Ciência do leite. Jaboticabal: UNESP, 2001. 287p.

PRATA, L.F.Distibuição de GMP* livre, em leites crus e pasteurizados, na definição da detecção de fraudes por adição de soro. Jaboticabal.UNESP. 2002.

PRATA, Luiz Francisco; ROIG, Salvador Massaguer; FUKUDA, Sandra Pereira. Correlação entre os métodos de ninidrina acidificada e HPLC para avaliar adição fraudulenta de soro em leite. Lait 84 (2004) 501-512. EDP Sciences, 2004.

PONSANO, E. H. G.; PINTO, M. F.; DELBEM, A. C. B.; LARA, J. A. F.de; PERRI, S. H. V. Avaliação da qualidade de amostras de leite cru comercializado no município de Araçatuba e potenciais riscos decorrentes de seu consumo. Revista Higiene Alimentar, v. 15, n. 86, p. 86, 2001.

OLIVEIRA, M. C. MPF/MG: operação ouro branco desarticula organização criminosas que adulteravam leite. 2009. Disponível em http://www.pgr.mpf.gov.br/noticias/noticias-dosite/criminal/operacao-ouro-branco-desarticula-organizacoes-criminosas-que-adeulteravam-leite-nosmunicipios-mineiros-de-uberaba-e-passos/.Acesso em 21 de março de 2010.

SWANSON, K. M. J, PETRAN, R. L. \& HANLIN, J. H. Culture methods for enumeration of microorganisms. In: DOWNES, F. P. \& ITO, K. (eds), Compendium of Methods for the Microbiological Examination of Foods, $4^{\text {th }}$ ed. Washington: American Public Health Association (APHA), 2001. Chapter 6, p. 53-67.

SILVA, Neusely da. Manual de métodos de análise microbiológica de alimentos. Valéria Christina Amstalden - São Paulo : Livraria Varela,1997, p31. 
SORIANO, C.; MICHEO, C.; MENDIEIRA, V.A.; TABERA, A.; STEFANO, A.; CASASNOVAS, G.; PURRÁN, P.; CORRADETTI, A.; CARABAJAL, S. Evaluación de la calidad de leche de tanque de tambos de la Cuenca Mar y Sierras. Veterinaria Argentina, v. 18, n. 179, p. 654-667, 2001.

TRONCO, Vânia. M. Manual para Inspeção da Qualidade do Leite. Santa Maria: RS: UFSM, 1997, Cap V, p.103-105.

VANDERZANT, C.; SPLITTSTOESSER, D. F. Compendium for the microbiological examination of foods. Washington, DC: American Public Health Association, 1992. 1219p.

ZANELA, M. B. et al. Qualidade do leite em sistemas de produção na região Sul do Rio Grande do Sul. Pesq. agropec. bras. [online]. 2006, vol.41, n.1, pp. 153-159.Figura 1: Exemplo de fotografia. 